\title{
Rubritalea marina gen. nov., sp. nov., a marine representative of the phylum 'Verrucomicrobia', isolated from a sponge (Porifera)
}

\author{
Correspondence \\ Ute Hentschel \\ ute.hentschel@mail.uni- \\ wuerzburg.de
}

\author{
Matthias Scheuermayer, ${ }^{1}$ Tobias A. M. Gulder, ${ }^{2}$ Gerhard Bringmann ${ }^{2}$ \\ and Ute Hentschel ${ }^{1}$ \\ 'Zentrum für Infektionsforschung, Universität Würzburg, Röntgenring 11, D-97070 Würzburg, \\ Germany \\ ²Lehrstuhl für Organische Chemie 1, Am Hubland, D-97074 Würzburg, Germany
}

\begin{abstract}
A marine bacterium, strain Pol012 ${ }^{\top}$, was isolated from the Mediterranean sponge Axinella polypoides and subsequently characterized as belonging to subphylum 1 of the phylum 'Verrucomicrobia'. Strain Pol012 ${ }^{\top}$ was non-motile, Gram-negative, coccoid or rod-shaped and red in colour. The menaquinones MK- 8 and MK- 9 were detected. The $\mathrm{G}+\mathrm{C}$ content of the genomic DNA was 50.9 mol\%. Growth was possible at temperatures between 8 and $30{ }^{\circ} \mathrm{C}$ and at $\mathrm{pH}$ values between $6 \cdot 8$ and $8 \cdot 2$. The closest cultured relative of strain Pol012 ${ }^{\top}$ was Akkermansia muciniphila (83\% sequence similarity), while the closest environmental 16S rRNA gene sequence was the marine clone Arctic96BD-2 (95\% sequence similarity). Strain Pol012 ${ }^{\top}$ is the first marine pure-culture representative of 'Verrucomicrobia' subphylum 1 and represents a novel genus and species, for which the name Rubritalea marina gen. nov., sp. nov. is proposed. The type strain is Pol012 ${ }^{\top}$ (=DSM $177716^{\top}=$ CIP $\left.108984^{\top}\right)$.
\end{abstract}

At present, six monophyletic subphyla are recognized (albeit not yet taxonomically validated formally) for the phylum 'Verrucomicrobia' on the basis of clone library studies (Hugenholtz et al., 1998; Vandekerckhove et al., 2000). While more than 500 different verrucomicrobial 16S rRNA gene sequences have been identified using $16 \mathrm{~S}$ rRNA genebased techniques, only a handful of them represent cultivated strains (Schlesner, 1987; Chin et al., 2001; Joseph et al., 2003; Sangwan et al., 2004). In fact, only two marine 'Verrucomicrobia' species, Alterococcus agarolyticus (Shieh \& Jean, 1998; Sangwan et al., 2004) and 'Fucophilus fucoidanolyticus' (Sakai et al., 2003), have been cultivated so far; both belong to subphylum 4 . The epixenosomes, ectosymbionts of marine ciliates of the genus Euplotidium, also belong to this subphylum (Petroni et al., 2000). In addition, verrucomicrobial 16S rRNA gene sequences have been recovered from marine animals and plants (Weidner et al., 2000; Alain et al., 2002; Bowman \& Nowak, 2004), from bacterioplankton (Bano \& Hollibaugh, 2002; Harris et al., 2004; O'Sullivan et al., 2004), from coastal Antarctic sediments (Bowman et al., 2000; Bowman \& McCuaig, 2003; Powell et al., 2003) and from seawater

Abbreviation: ASW, artificial seawater.

The GenBank/EMBL/DDBJ accession number for the 16S rRNA gene sequence of strain Pol012 ${ }^{\top}$ is DQ302104, and those for verrucomicrobial 16S rRNA gene sequences from sponges and seawater are DQ302105-DO302120.
(Schäfer et al., 2000; Madrid et al., 2001; Suzuki et al., 2001; Bano \& Hollibaugh, 2002; O'Sullivan et al., 2004). The respective organisms are mainly affiliated with subphyla 1 and 4. In this study, we describe the cultivation and analysis of strain Pol012 ${ }^{\mathrm{T}}$, the first marine member of subphylum 1 of the phylum 'Verrucomicrobia'. In addition, 16S rRNA gene sequences of various members of the 'Verrucomicrobia' were isolated from sponges and seawater.

Strain Pol012 ${ }^{\mathrm{T}}$ was isolated from the Mediterranean sponge Axinella polypoides on M1 agar (Mincer et al., 2002). Sponges of the species Axinella polypoides, Axinella damicornis and Aplysina aerophoba were collected by means of scuba-diving offshore from Banyuls-sur-Mer, France $\left(42^{\circ} 29^{\prime} \mathrm{N} 03^{\circ} 08^{\prime} \mathrm{E}\right)$ in May 2003. Sponges of the species Agelas conifera and Aplysina fistularis were collected in July 2000 offshore from Little San Salvador Island in the Bahamas (GPS: $24^{\circ} 34 \cdot 39^{\prime} \mathrm{N} 75^{\circ} 58 \cdot 00^{\prime} \mathrm{W}$ ) at depths of 5-15 m. Mechanical separation of the sponge tissue and storage of the bacterial cells were performed as described by Fieseler et al. (2004). For further cultivation of strain Pol012 ${ }^{\mathrm{T}}$, Verrucomicrobium spinosum medium 607 (Deutsche Sammlung von Mikroorganismen und Zellkulturen, Braunschweig, Germany) was modified to contain the following: $1.5 \mathrm{~g}$ yeast extract, $1.5 \mathrm{~g}$ peptone, $1.5 \mathrm{~g}$ glucose, $20 \mathrm{ml}$ Hutner's basal salts solution (CohenBazire et al., 1957), $5 \mathrm{ml}$ Tris/ $\mathrm{HCl}(1 \mathrm{M}, \mathrm{pH} \mathrm{7 \cdot 5})$ and $975 \mathrm{ml}$ artificial seawater (ASW) (Lyman \& Fleming, 1940). The new medium designed for the cultivation of marine 
members of the phylum 'Verrucomicrobia' was named 'Ver100'. Strain Pol012 ${ }^{\mathrm{T}}$ was incubated at $30^{\circ} \mathrm{C}$ on plates and in liquid cultures shaken at 200 r.p.m. On the newly designed marine medium (Ver100), strain Pol012 ${ }^{\mathrm{T}}$ formed soft, red colonies, while the liquid cultures were pink to red in colour. Growth was observed at temperatures between 8 and $30^{\circ} \mathrm{C}$, but not at 4 or $35^{\circ} \mathrm{C}$. Cell growth was optimal at temperatures between 25 and $30{ }^{\circ} \mathrm{C}$. Strain Pol012 ${ }^{\mathrm{T}}$ was not able to grow on Ver 100 agar plates incubated in an anaerobic jar. Vitamins were not required for growth.

Strain Pol012 $2^{\mathrm{T}}$ showed a strict requirement for seawater. Growth was possible in liquid culture with media formulations containing 60-160\% (v/v) ASW, while growth was inhibited below $40 \%$ or above $180 \%$ ASW. Replacement of ASW with $\mathrm{NaCl}$ was not possible, since no growth could be observed in medium containing $0,200,400,510,610,800$, 1070 or $1600 \mathrm{mM} \mathrm{NaCl}$. Growth was possible at $\mathrm{pH}$ values between $6 \cdot 8$ and $8 \cdot 2$, but not at $6 \cdot 0 ; \mathrm{pH}$ values above $8 \cdot 2$ could not be measured, since unknown salts precipitated in Ver100 culture medium. The cells grew poorly on ZoBell agar (Oppenheimer \& ZoBell, 1952) and slightly better on M1 agar (Mincer et al., 2002), on which strain Pol012 ${ }^{\mathrm{T}}$ was originally isolated. In liquid culture, strain Pol012 ${ }^{\mathrm{T}}$ was able to grow in minimal Ver100 medium (lacking peptone, yeast extract and glucose) with glucose, xylose, melibiose, cellobiose, lactose, pyruvate or pectin serving as the sole energy source. Growth was not possible with galactose, fructose, mannose, mannitol, arabinose, sucrose, ribose, sorbose, fucose, rhamnose, melitose, ethanol, methanol, glycerol, galacturonic acid, malate, tartrate, citrate, glycine, alanine, leucine, isoleucine, proline, lysine, glutamate, starch, xylan or chitin. The polysaccharides were tested at $0.1 \%(\mathrm{w} / \mathrm{v})$. All other substances were tested at a concentration of $10 \mathrm{mM}$.

For further phenotypic testing, Pol012 ${ }^{\mathrm{T}}$ was grown on Ver100 agar plates for $48 \mathrm{~h}$ at $30^{\circ} \mathrm{C}$ and resuspended in either ASW or Ver100 minimal medium. Using the API ZYM system (bioMérieux), the enzymes alkaline phosphatase, esterase (C4), esterase lipase (C8), leucine arylamidase, trypsin, acid phosphatase and naphthol-AS-BI-phosphohydrolase gave positive results. Using the API 20NE system (bioMérieux), $\beta$-glucosidase activity on aesculin, $\beta$-galactosidase activity on 4-nitrophenyl $\beta$-D-galactopyranoside and oxidase activity were found. Furthermore, reduction of nitrate to nitrite was measurable. Using Biolog GN2 microplates, strain Pol012 ${ }^{\mathrm{T}}$ was shown to oxidize dextrin, D-cellobiose, D-fructose, D-galactose, $\alpha$-D-glucose, D-mannose, D-melibiose, acetic acid and formic acid. Here, cells were suspended in Ver100 minimal medium to an $\mathrm{OD}_{600}$ of $0 \cdot 3$. All results were read after incubation at $30{ }^{\circ} \mathrm{C}$ $(n=3)$.

Strain Pol012 ${ }^{\mathrm{T}}$ was able to grow in Ver100 culture medium supplemented with vancomycin, kanamycin, streptomycin, gentamicin, neomycin or tetracycline (each at a concentration of $100 \mu \mathrm{g} \mathrm{ml}^{-1}$ ), but not with chloramphenicol, ampicillin, lincomycin, erythromycin or oxacillin (each at a concentration of $10 \mu \mathrm{g} \mathrm{m}{ }^{-1}$ ). Strain Pol012 ${ }^{\mathrm{T}}$ was tested for antimicrobial activity against Gram-positive Staphylococcus aureus and Gram-negative Escherichia coli reference strains. Neither soft-agar overlays performed with Pol012 ${ }^{\mathrm{T}}$ following growth on agar plates nor ethyl acetate extracts of liquid cultures provided evidence of antimicrobial activity.

Cells of strain Pol012 $2^{\mathrm{T}}$ produced a red pigment that did not diffuse into the agar and which could be easily extracted with methanol or ethanol. Cell-free ethanol extracts displayed an absorption maximum at $495 \mathrm{~nm}$. Cells were catalasenegative and oxidase-positive. Quinones MK-8 (23\%) and MK-9 (77\%) could be detected. This is consistent with other members of the phylum 'Verrucomicrobia', in which menaquinones have also been identified (Sittig \& Schlesner, 1993; Hedlund et al., 1996; Sakai et al., 2003; Sangwan et al., 2004). The G + C content of the genomic DNA was $50.9 \mathrm{~mol} \%$. The peptidoglycan structure of strain Pol012 ${ }^{\mathrm{T}}$ contained direct cross-linkages of the A1 $\gamma$ mesodiaminopimelic acid type that is also present in 'Chthoniobacter flavus' from subphylum 2 of the phylum Verrucomicrobia (Sangwan et al., 2004); meso-diaminopimelic acid has also been isolated from Prosthecobacter strains (Hedlund et al., 1996). The major cellular fatty acids were hexadecanoic acid $\left(\mathrm{C}_{16: 0} ; 23 \%\right.$ of the total), 12-methyltridecanoic acid (i- $\mathrm{C}_{14: 0} ; 22 \%$ of the total), cis-9-hexadecenoic acid and/or 2-hydroxy-13-methyltetradecanoic acid $\left(\mathrm{C}_{16: 1} \omega 7 c\right.$ and/or $2-\mathrm{OH}$ i- $\mathrm{C}_{15: 0} ; 21.5 \%$ of the total $), 12-$ methyltetradecanoic acid $\left(\mathrm{a}-\mathrm{C}_{15: 0} ; 6 \%\right.$ of the total) and pentadecanoic acid $\left(\mathrm{C}_{15: 0} ; 4 \cdot 5 \%\right.$ of the total $)$. Extraction and analysis of the cellular fatty acids and the isoprenoid quinones, analysis of the peptidoglycan structure and determination of the $\mathrm{G}+\mathrm{C}$ content of the genomic DNA were performed by the Deutsche Sammlung von Mikroorganismen und Zellkulturen.

Transmission electron microscopy of ultrathin sections of strain Pol012 $2^{\mathrm{T}}$ was performed essentially as described by Pimentel-Elardo et al. (2003). For transmission electron microscopy of negatively stained whole cells, bacteria were grown in liquid culture and fixed with $2 \cdot 5 \%$ glutaraldehyde. A drop of culture was incubated on a copper grid, the liquid was removed and the cells were stained with a drop of $0.5 \%$ uranyl acetate for $5 \mathrm{~min}$. The cells were examined under an EM 10 electron microscope (Zeiss). For scanning electron microscopy, colonies with surrounding material were fixed in $6.25 \%$ glutaraldehyde, washed three times with $0.1 \mathrm{M}$ cacodylate buffer and dehydrated with increasing concentrations of acetone (from 30 to $100 \%$ ). After critical-point drying and platinum coating of the dried material, colonies were examined with a DSM 962 scanning electron microscope (Zeiss). Strain Pol012 ${ }^{\mathrm{T}}$ grew in various forms including almost coccoid cells ranging from 0.5 to $1 \cdot 1 \mu \mathrm{m}$ in diameter and rod-shaped cells ranging in length from 0.6 to $1.8 \mu \mathrm{m}$ and in width from 0.4 to $1.0 \mu \mathrm{m}$ (Figs 1 and 2 ). Electron microscopic images of 35 negatively stained cells were used to measure cell size. Single cells and cell clusters were found. Cell division might occur by budding (see 


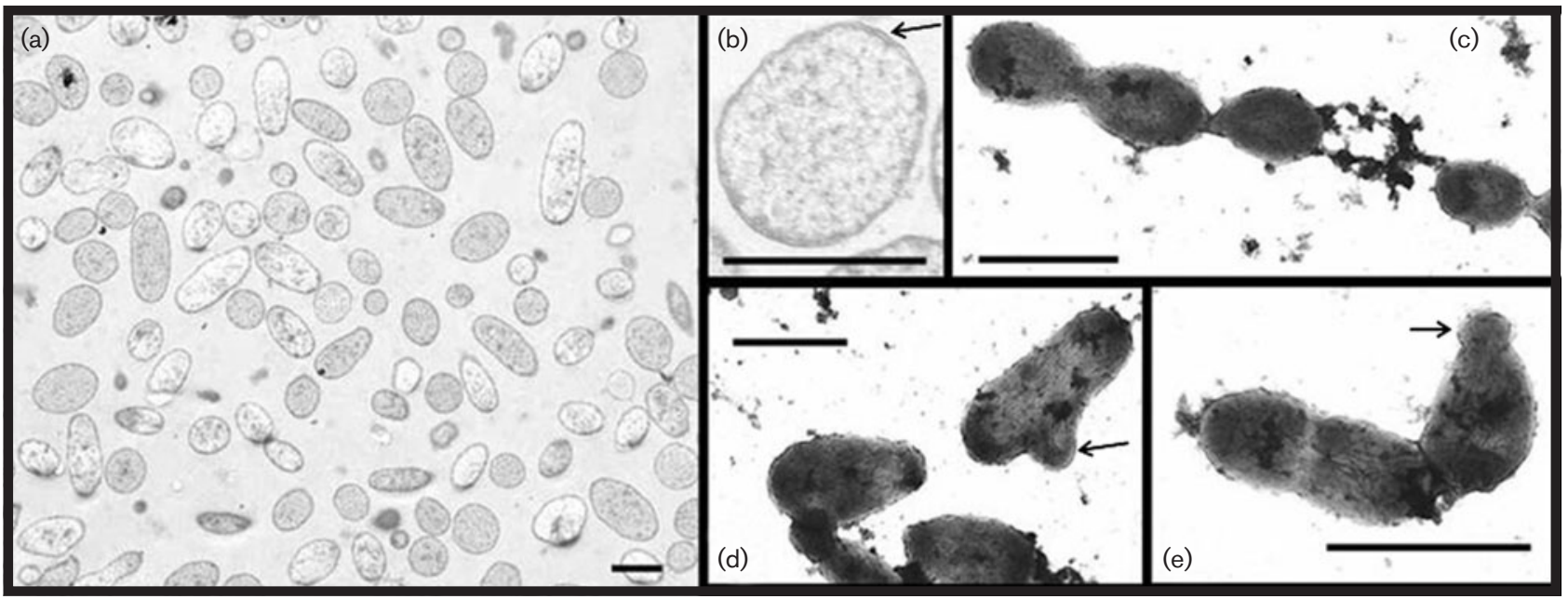

Fig. 1. $(a, b)$ Transmission electron micrographs of ultrathin sections of cells of strain Pol012 ${ }^{\top}$. (c, d, e) Transmission electron micrographs of negatively stained whole cells of strain Pol012 ${ }^{\top}$. Bars, $1 \mu \mathrm{m}$.

arrows in Fig. 1d, e). Motile cells, flagella and prosthecae were not observed. Strain Pol012 ${ }^{\mathrm{T}}$ stained Gram-negative, and two separate membranes could be detected by electron microscopy (see arrow in Fig. 1b).

16S rRNA gene amplification, cloning and sequencing were performed according to the methods of Hentschel et al. (2001), using universal bacterial primers $27 \mathrm{f}$ and 1492r (Lane, 1991). For the amplification of verrucomicrobial 16S rRNA genes, the 'Verrucomicrobia'-specific forward primer Ver53F (Stevenson et al., 2004) and the reverse primer 1492r were used. Sequences were checked for chimaeras (Huber et al., 2004), and phylogenetic analyses were performed using the ARB software package (Strunk et al., 2000) after alignment of the sequences by using CLUSTAL W. All sequences contained at least $1250 \mathrm{nt}$. Phylogenetic-tree construction was performed using the neighbour-joining method with bootstrap values based on 1000 replications. Phylogenetic analysis of the 16S rRNA gene sequence of strain Pol $012^{\mathrm{T}}$ revealed a sequence similarity of $83 \%$ with respect to its closest cultured relative, Akkermansia muciniphila (Derrien et al., 2004), and a sequence similarity of $95 \%$ with respect to the closest environmental clone, Arctic96BD-2 (Bano \& Hollibaugh, 2002). It was concluded that strain $\mathrm{Pol} 012^{\mathrm{T}}$ is affiliated to verrucomicrobial subphylum 1. This clade includes the freshwater isolate $V$. spinosum (Schlesner, 1987), four freshwater Prosthecobacter species (Hedlund et al., 1997), the human intestinal isolate Akkermansia muciniphila (Derrien et al., 2004) and several environmental 16S rRNA gene sequences. Strain Pol012 represents the first cultivated marine isolate of this subphylum (Fig. 3).

\section{Natural habitat of isolate Pol012 ${ }^{\mathrm{T}}$}

Members of the phylum 'Verrucomicrobia' have been reported as symbionts of eukaryotes (Petroni et al., 2000; Vandekerckhove et al., 2000) and as being associated with marine animals and plants (Alain et al., 2002; Bowman \& Nowak, 2004; Weidner et al., 2000). In this study, a novel marine isolate, strain Pol012 ${ }^{\mathrm{T}}$, was isolated from a marine sponge. In addition, several verrucomicrobial $16 \mathrm{~S}$ rRNA

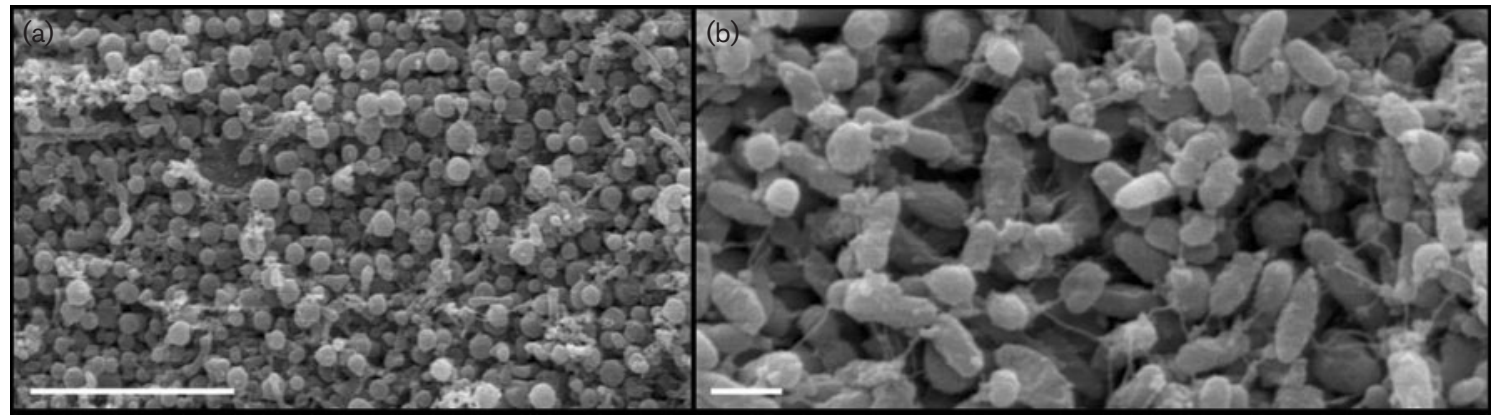

Fig. 2. (a, b) Scanning electron micrographs of cells of strain Pol012 ${ }^{\top}$ growing on agar plates. Bars: (a) $10 \mu \mathrm{m}$; (b) $1 \mu \mathrm{m}$. 


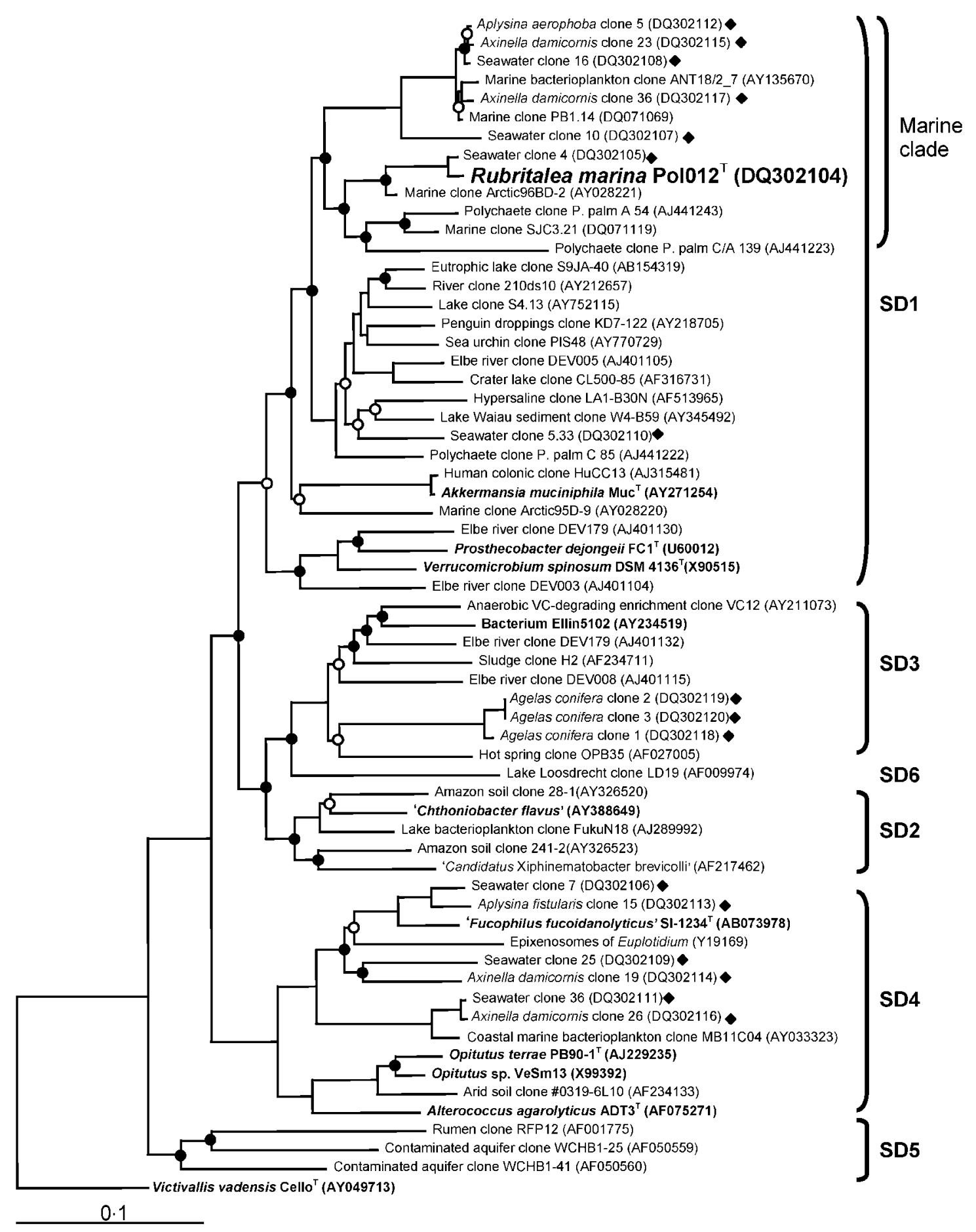

Fig. 3. Phylogenetic analysis of $16 \mathrm{~S}$ rRNA gene sequences from cultured and uncultured representatives of the phylum 'Verrucomicrobia'. The tree was generated by the neighbour-joining method from the ARB package and was visualized with TREEVIEW. Subphyla are labelled according to Hugenholtz et al. (1998) (SD1-SD5) and Vandekerckhove et al. (2000) (SD6). The marine clade within subphylum 1 is indicated by a bracket. Open circles indicate bootstrap values between 50 and $75 \%$ and closed circles indicate bootstrap values above $75 \%$ (1000 replicates). Diamond symbols indicate sponge- or seawaterderived environmental sequences obtained in this study. Sequences from cultured members of the phylum 'Verrucomicrobia' are shown in bold. Victivallis vadensis (Zoetendal et al., 2003) was used as an outgroup. Bar, $10 \%$ sequence divergence. 
gene sequences were recovered from marine sponges and seawater, thus extending the range of environmental sources from which these bacteria can be isolated.

Sponges are filter-feeders that are capable of efficiently removing bacteria and small eukaryotes from seawater and translocating the food particles into their interior, where they are digested by means of phagocytosis. Sponges are also known to contain phylogenetically complex microbial communities within their tissues: these communities can amount to up to $40 \%$ of the animal's biomass (Hill, 2004; Hentschel et al., 2006; Scheuermayer et al., 2006). The formation of monophyletic, sponge-specific sequence clusters in at least eight different bacterial phyla has been taken as evidence of a stable, and possibly symbiotic, association between the corresponding micro-organisms and their sponge host (e.g. Hentschel et al., 2002; Fieseler et al., 2004; Montalvo et al., 2005). In contrast to previous studies on sponge-microbe associations, monophyletic cluster formation is not evident for the verrucomicrobial sequences recovered in this study (Fig. 3; sequences indicated by diamond symbols). Instead, the Pol012 ${ }^{\mathrm{T}} 16 \mathrm{~S}$ rRNA gene sequence is most closely related to a seawater $16 \mathrm{~S}$ rRNA gene sequence from the collection site $(>98 \%$ sequence similarity). Similarly, other sponge-derived verrucomicrobial $16 \mathrm{~S}$ rRNA gene sequences were also more closely related to seawater sequences than to those from various sponges. This indicates that marine members of the phylum 'Verrucomicrobia' can principally be isolated from sponges, but that seawater is also a likely source for this novel clade of micro-organisms. Further investigation is needed to determine whether the association of marine strain Pol012 ${ }^{\mathrm{T}}$ with Axinella polypoides is coincidental or whether Pol012 ${ }^{\mathrm{T}}$ and related strains should be considered symbionts.

\section{Description of Rubritalea gen. nov.}

Rubritalea (Ru.bri.ta'lea. L. adj. ruber red; L. fem. n. talea a rod, staff; N.L. fem. n. Rubritalea a red-coloured rod).

Cells are Gram-negative, non-motile, coccoid or rodshaped, obligately marine and red in colour. Metabolism is aerobic and chemo-organotrophic.

\section{Description of Rubritalea marina sp. nov.}

Rubritalea marina (ma.ri'na. L. fem. adj. marina of or belonging to the sea, marine).

Cells are Gram-negative, non-motile, coccoid or rodshaped, and red in colour. Able to grow with glucose, xylose, melibiose, cellobiose, lactose, pyruvate or pectin as the sole energy source under aerobic conditions. Does not grow anaerobically. The DNA G $+\mathrm{C}$ content is $50.9 \mathrm{~mol} \%$. The major cellular fatty acids are hexadecanoic acid, 12-methyltridecanoic acid, cis-9-hexadecenoic acid and/or 2-hydroxy-13-methyltetradecanoic acid, 12-methyltetradecanoic acid and pentadecanoic acid. Menaquinones MK-8 and MK-9 are present. The peptidoglycan of the cell wall contains direct cross-linkages of the A $1 \gamma$ meso-diaminopimelic acid type. Strain Pol012 ${ }^{\mathrm{T}}$ tests negative for catalase and positive for oxidase, alkaline phosphatase, esterase (C4), esterase lipase (C8), leucine arylamidase, trypsin, acid phosphatase, naphthol-AS-BI-phosphohydrolase, $\beta$-glucosidase and $\beta$-galactosidase. Strain Pol012 ${ }^{\mathrm{T}}$ is capable of nitrate reduction to nitrite and oxidation of dextrin, Dcellobiose, D-fructose, D-galactose, $\alpha$-D-glucose, D-mannose, D-melibiose, acetic acid and formic acid. Strain Pol012 ${ }^{\mathrm{T}}$ is able to grow in medium containing $60-160 \%$ ASW, at $\mathrm{pH}$ values between 6.8 and 8.2 and at temperatures between 8 and $30^{\circ} \mathrm{C}$.

The type strain, Pol012 ${ }^{\mathrm{T}}\left(=\mathrm{DSM} 177716^{\mathrm{T}}=\mathrm{CIP} 108984^{\mathrm{T}}\right)$, was isolated from the Mediterranean sponge Axinella polypoides.

\section{Acknowledgements}

We gratefully acknowledge the marine-operations personnel at the Laboratoire Arago (Banyuls-sur-Mer, France) for help during sponge collection, and P. Hugenholtz (Walnut Creek, CA, USA) for advice. Christine Gernert (Würzburg, Germany) is acknowledged for excellent technical assistance. Financial support was provided by the Deutsche Forschungsgemeinschaft (grant SFB630 'Recognition, Preparation, and Functional Analysis of Agents against Infectious Diseases') to U. H.

\section{References}

Alain, K., Olagnon, M., Desbruyères, D., Pagé, A., Barbier, G., Juniper, S. K., Quérellou, J. \& Cambon-Bonavita, M.-A. (2002). Phylogenetic characterization of the bacterial assemblage associated with mucous secretions of the hydrothermal vent polychaete Paralvinella palmiformis. FEMS Microbiol Ecol 42, 463-476.

Bano, N. \& Hollibaugh, J. T. (2002). Phylogenetic composition of bacterioplankton assemblages from the Arctic Ocean. Appl Environ Microbiol 68, 505-518.

Bowman, J. P. \& McCuaig, R. D. (2003). Biodiversity, community structural shifts, and biogeography of prokaryotes within Antarctic continental shelf sediment. Appl Environ Microbiol 69, 2463-2483.

Bowman, J. P. \& Nowak, B. (2004). Salmonid gill bacteria and their relationship to amoebic gill disease. J Fish Dis 27, 483-492.

Bowman, J. P., Rea, S. M., McCammon, S. A. \& McMeekin, T. A. (2000). Diversity and community structure within anoxic sediment from marine salinity meromictic lakes and a coastal meromictic marine basin, Vestfold Hilds, Eastern Antarctica. Environ Microbiol 2, 227-237.

Chin, K.-J., Liesack, W. \& Janssen, P. H. (2001). Opitutus terrae gen. nov., sp. nov., to accommodate novel strains of the division 'Verrucomicrobia' isolated from rice paddy soil. Int J Syst Evol Microbiol 51, 1965-1968.

Cohen-Bazire, G., Sistrom, W. R. \& Stanier, R. Y. (1957). Kinetic studies of pigment synthesis by non-sulfur purple bacteria. J Cell Comp Physiol 49, 25-68.

Derrien, M., Vaughan, E. E., Plugge, C. M. \& de Vos, W. M. (2004). Akkermansia muciniphila gen. nov., sp. nov., a human intestinal mucin-degrading bacterium. Int J Syst Evol Microbiol 54, 1469-1476.

Fieseler, L., Horn, M., Wagner, M. \& Hentschel, U. (2004). Discovery of the novel candidate phylum 'Poribacteria' in marine sponges. Appl Environ Microbiol 70, 3724-3732. 
Harris, J. K., Kelley, S. T. \& Pace, N. R. (2004). New perspective on uncultured bacterial phylogenetic division OP11. Appl Environ Microbiol 70, 845-849.

Hedlund, B. P., Gosink, J. J. \& Staley, J. T. (1996). Phylogeny of Prosthecobacter, the fusiform caulobacters: members of a recently discovered division of the Bacteria. Int J Syst Bacteriol 46, 960-966.

Hedlund, B. P., Gosink, J. J. \& Staley, J. T. (1997). Verrucomicrobia div. nov., a new division of the Bacteria containing three new species of Prosthecobacter. Antonie van Leeuwenhoek 72, 29-38.

Hentschel, U., Schmid, M., Wagner, M., Fieseler, L., Gernert, C. \& Hacker, J. (2001). Isolation and phylogenetic analysis of bacteria with antimicrobial activities from the mediterranean sponges Aplysina aerophoba and A. cavernicola. FEMS Microbiol Ecol 35, 305-312.

Hentschel, U., Hopke, J., Horn, M., Friedrich, A. B., Wagner, M. \& Moore, B. S. (2002). Molecular evidence for a uniform microbial community in sponges from different oceans. Appl Environ Microbiol 68, 4431-4440.

Hentschel, U., Usher, K. M. \& Taylor, M. W. (2006). Marine sponges as microbial fermenters. FEMS Microbiol Ecol 55, 167-177.

Hill, R. T. (2004). Microbes from marine sponges: a treasure trove of biodiversity for natural products discovery. In Microbial Diversity and Bioprospecting, pp. 177-190. Edited by A. T. Bull. Washington, DC: American Society for Microbiology.

Huber, T., Faulkner, G. \& Hugenholtz, P. (2004). Bellerophon; a program to detect chimeric sequences in multiple sequence alignments. Bioinformatics 20, 2317-2319.

Hugenholtz, P., Goebel, B. M. \& Pace, N. R. (1998). Impact of culture-independent studies on the emerging phylogenetic view of bacterial diversity. J Bacteriol 180, 4765-4774.

Joseph, S. J., Hugenholtz, P., Sangwan, P., Osborne, C. A. \& Janssen, P. H. (2003). Laboratory cultivation of widespread and previously uncultured soil bacteria. Appl Environ Microbiol 69, 2391-2396.

Lane, D. J. (1991). 16S/23S rRNA sequencing. In Nucleic Acid Techniques in Bacterial Systematics, pp. 115-175. Edited by E. Stackebrandt \& M. Goodfellow. New York: Wiley.

Lyman, J. \& Fleming, R. H. (1940). Composition of seawater. J Mar Res 3, 134-146.

Madrid, V. M., Taylor, G. T., Scranton, M. I. \& Christoserdov, A. Y. (2001). Phylogenetic diversity of bacterial and archeal communities in the anoxic zone of the Cariaco Basin. Appl Environ Microbiol 67, $1663-1674$.

Mincer, T. J., Jensen, P. R., Kauffman, C. A. \& Fenical, W. (2002). Widespread and persistent populations of a major new actinomycete taxon in ocean sediments. Appl Environ Microbiol 68, 5005-5011.

Montalvo, N. F., Mohamed, N. M., Enticknap, J. J. \& Hill, R. T. (2005). Novel actinobacteria from marine sponges. Antonie van Leeuwenhoek 87, 29-36.

Oppenheimer, C. H. \& ZoBell, C. E. (1952). The growth and viability of sixty-three species of marine bacteria as influenced by hydrostatic pressure. J Mar Res 11, 10-18.

O'Sullivan, L. A., Fuller, K. E., Thomas, E. M., Turley, C. M., Fry, J. C. \& Weightman, A. J. (2004). Distribution and culturability of the uncultivated 'AGG58 cluster' of the Bacteroidetes phylum in aquatic environments. FEMS Microbiol Ecol 47, 359-370.
Petroni, G., Spring, S., Schleifer, K.-H., Verni, F. \& Rosati, G. (2000). Defensive extrusive ectosymbionts of Euplotidium (Ciliophora) that contain microtubule-like structures are bacteria related to Verrucomicrobia. Proc Natl Acad Sci U S A 97, 1813-1817.

Pimentel-Elardo, S., Wehrl, M., Friedrich, A. B., Jensen, P. J. \& Hentschel, U. (2003). Isolation of planctomycetes from Aplysina sponges. Aquat Microb Ecol 33, 239-245.

Powell, S. M., Bowman, J. P., Snape, I. \& Stark, J. S. (2003). Microbial community variation in pristine and polluted coastal Antarctic sediments. FEMS Microbiol Ecol 45, 135-145.

Sakai, T., Ishizuka, K. \& Kato, I. (2003). Isolation and characterization of a fucoidan-degrading marine bacterium. Mar Biotechnol 5, 409-416.

Sangwan, P., Chen, X., Hugenholtz, P. \& Janssen, P. H. (2004). Chthoniobacter flavus gen. nov., sp. nov., the first pure-culture representative of subdivision two, Spartobacteria classis nov., of the phylum Verrucomicrobia. Appl Environ Microbiol 70, 5875-5881.

Schäfer, H., Servais, P. \& Muyzer, G. (2000). Successional changes in the genetic diversity of a marine bacterial assemblage during confinement. Arch Microbiol 173, 138-145.

Scheuermayer, M., Pimentel-Elardo, S., Fieseler, L., Grozdanov, L. \& Hentschel, U. (2006). Microorganisms of sponges: phylogenetic diversity and biotechnological potential. In Frontiers in Marine Biotechnology, pp. 289-312. Edited by P. Proksch \& W. E. G. Müller. Norwich: Horizon Bioscience.

Schlesner, H. (1987). Verrucomicrobium spinosum gen. nov., sp. nov., a fimbriated prosthecate bacterium. Syst Appl Microbiol 10, 54-56.

Shieh, W. Y. \& Jean, W. D. (1998). Alterococcus agarolyticus, gen. nov., sp. nov., a halophilic thermophilic bacterium capable of agar degradation. Can J Microbiol 44, 637-645.

Sittig, M. \& Schlesner, H. (1993). Chemotaxonomic investigation of various prosthecate and/or budding bacteria. Syst Appl Microbiol 16, 92-103.

Stevenson, B. S., Eichorst, S. A., Wertz, J. T., Schmidt, T. M. \& Breznak, J. A. (2004). New strategies for cultivation and detection of previously uncultured microbes. Appl Environ Microbiol 70, $4748-4755$.

Strunk, O., Gross, O., Reichel, B. \& 10 other authors (2000). ARB: a software environment for sequence data (http://www.mikro. biologie.tu-muenchen.de). Department of Microbiology, Technische Universität Munich, Germany.

Suzuki, M. T., Béjà, O., Taylor, L. T. \& DeLong, E. F. (2001). Phylogenetic analysis of ribosomal RNA operons from uncultivated coastal marine bacterioplankton. Environ Microbiol 3, 323-331.

Vandekerckhove, T. T. M., Willems, A., Gillis, M. \& Coomans, A. (2000). Occurrence of novel verrucomicrobial species, endosymbiotic and associated with parthenogenesis in Xiphinema americanumgroup species (Nematoda, Longidoridae). Int J Syst Evol Microbiol 50, 2197-2205.

Weidner, S., Arnold, W., Stackebrandt, E. \& Pühler, A. (2000). Phylogenetic analysis of bacterial communities associated with leaves of the seagrass Halophila stipulacea by a culture-independent smallsubunit rRNA gene approach. Microb Ecol 39, 22-31.

Zoetendal, E. G., Plugge, C. M., Akkermans, A. D. L. \& de Vos, W. M. (2003). Victivallis vadensis gen. nov., sp. nov., a sugar-fermenting anaerobe from human faeces. Int J Syst Evol Microbiol 53, 211-215. 